\title{
THE LOGICS OF BIOPOWER AND THE WAR ON TERROR
}





\section{THE LOGICS OF BIOPOWER AND THE WAR ON TERROR}

\section{LIVING, DYING, SURVIVING}

Edited by

Elizabeth Dauphinee and

Cristina Masters 
THE LOGICS OF BIOPOWER AND THE WAR ON TERROR

(C) Elizabeth Dauphinee and Cristina Masters, 2007

Softcover reprint of the hardcover 1st edition 2007 978-1-4039-7465-5

All rights reserved. No part of this book may be used or reproduced in any manner whatsoever without written permission except in the case of brief quotations embodied in critical articles or reviews.

First published in 2007 by

PALGRAVE MACMILLAN'M

175 Fifth Avenue, New York, N.Y. 10010 and

Houndmills, Basingstoke, Hampshire, England RG21 6XS

Companies and representatives throughout the world.

PALGRAVE MACMILLAN is the global academic imprint of the Palgrave Macmillan division of St. Martin's Press, LLC and of Palgrave Macmillan Ltd. Macmillan ${ }^{\circledR}$ is a registered trademark in the United States, United Kingdom and other countries. Palgrave is a registered trademark in the European Union and other countries.

ISBN 978-1-349-73729-1 ISBN 978-1-137-04379-5 (eBook) DOI 10.1007/978-1-137-04379-5

Library of Congress Cataloging-in-Publication Data Hawaii)

International Studies Association, Meeting (46th : 2005 : Honolulu,

The logics of biopower and the war on terror : living, dying, surviving /

Elizabeth Dauphinee and Cristina Masters (eds.).

p. $\mathrm{cm}$.

Papers from a roundtable delivered at the 46th Annual Convention of the International Studies Association in Mar. 2005 in Honolulu, Hawaii. Includes bibliographical references and index.

1. War on Terrorism, 2001-Social aspects-United StatesCongresses. 2. Violence-Political aspects-United States-Congresses. 3. Biopolitics-United States-Congresses. 4. Popular culture-Political aspects-United States-Congresses. 5. United States-Politics and government-2001-Congresses. 6. United States - Social conditions1980-Congresses. I. Dauphinee, Elizabeth, 1974-. II. Masters, Cristina, 1974- III. Title.

HV6432.157 2007

$303.6^{\prime} 2502-\mathrm{dc} 22$

2006048569

A catalogue record for this book is available from the British Library.

Design by Newgen Imaging Systems (P) Ltd., Chennai, India.

First edition: January 2007

10987654321

Transferred to Digital Printing 2011 


\section{CONTENTS}

Introduction: Living, Dying, Surviving I

vii

Elizabeth Dauphinee and Cristina Masters

\section{Part I Bodies, Lives, Deaths}

1 Crossroads of Death

Roxanne Lynn Doty

2 Missing Persons: Manhattan, September 2001 Jenny Edkins

3 Body Counts: The Biopolitics of Death

Cristina Masters

\section{Part II Cinematics, Culture, Aesthetics}

4 Responsibility and Terror: Visual Culture and Violence in the Precarious Life

Mark J. Lacy

5 Persistence of Memory? The (New) Surrealism of American Security Policy

Kyle Grayson

6 Securitizing the Unconscious: The Bush

Doctrine of Preemption and Minority Report

Cynthia Weber

7 The Biopolitics of Security: Oil, Empire, and the Sports Utility Vehicle

David Campbell 


\section{Part III Regulation, Securitization, Preemption}

8 Sovereign Contradictions: Maher Arar and the Indefinite Future

David Mutimer

9 Abject Spaces: Frontiers, Zones, Camps

Engin F. Isin and Kim Rygiel

10 Biopolitics and the Tragic Subject of Human Rights

Anne Orford

11 Living, Dying, Surviving II Elizabeth Dauphinee 


\title{
INTRODUCTION: LIVING, DYING, SURVIVING I
}

\author{
Elizabeth Dauphinee and Cristina Masters
}

Collected in this volume are stories about the stories we tell. They are bodies and human lives, and they explore the logics and contexts in which particular forms of violence are made possible and sustained. One of those contexts is the war on terror, though it is not the only one. The war on terror animates particular forms of political violence, while simultaneously obscuring the historical contexts in which these violences have emerged. Ascribing the violence of our current political situation to the events of September 11 and their aftermath erases the fact that many of these practices are not new. They have varying depths of historical salience that are rooted in the disciplinary representations associated with state and identity formation. In many ways, what September 11 introduces is a terrain of unquestionability and ineluctability, which in turn forms the "perfect alibi" for the evacuation of politics from memory. The violences that this volume foregrounds are, in the context of the war on terror, understood to be "necessary"-even "common sense." Particular individuals pose threats; terrorism requires response and containment; "rogue states" and "states of concern" must be acted against. In many ways, however, the war on terror is not what its architects claim it to be: it is both less and more and other than. The war on terror levels an obvious gaze at the places we expect to find it: in the narrow field of vision associated with "what counts" as "international relations"-in states and the administration of states and in the battlefields of war (physical, cyber, informational). But the war on terror also produces 
violences in the spaces where our gaze is not-where our disciplinary vision is murkier. To recognize this is to tell different stories and to tell stories differently.

Collected here are stories that ask questions not commonly associated with the war on terror-indeed, many of them ask questions that undermine and disturb the logics that are said to make the war on terror a necessary facet of contemporary global political practice. They are stories that ask personal questions. Very often they are painful questions. They are stories that inquire after the missing, the deported, the detained, the deremembered, and the dead. By extension, they are also stories that ask us to ask ourselves who we think "we" are, and what the political imaginaries associated with that "we" demand of both ourselves and others. The authors of this volume find their stories in experiences of the everyday - and, indeed, the war on terror has become the everyday-even the mundaneleaking into the ordinary spaces of human lives in the form of airport security screening, the price of gasoline, and the entertainment we choose. But we might also say that the war on terror as produced in the experience of the everyday in turn produces spaces of the exceptional. Indeed, the violence that animates the practices associated with the war on terror increasingly produces an elision between the everyday and the exceptional. The exceptional bleeds into the everyday, and many of the lives chronicled in this volume are marked by a measure of exceptional violence that has, disturbingly, become the everyday. In this sense, we write, and perhaps should write, less as scholars and more as witnesses.

By extension, the stories in this volume can also be read as a mode of questioning. Each in its turn seeks to engage in an ethos of questioning with the aim of recovering the lives that are caught in the logics of sovereign biopower. In this way, it serves to unmask and refuse many of the questions that are associated with the war on terror-questions that inquire after citizenship status, place of birth and upbringing, religious and ethnic background, the language one speaks, and the friends one keeps. We know that questions always designate the form that answers can take. In the context of the war on terror, the dominant mode of questioning is one that seeks to constitute and mobilize particular subjects in ways that inevitably flatten the fragmented-and the political-textures of lived lives. Almost immediately following the attacks on the World Trade Center, a narrative emerged that sought to cohere and mobilize those whose lives were lost. The narrative became one of heroes, of sacrifice for the state, which in turn comprised the animating subject for the war(s) that followed, and perhaps for wars that are yet to come. These are narratives that thread the relationships between the bodies and lives of victims through the body and life of 
the state and through the public domain such that the victims were said to belong to all Americans. But, as Jenny Edkins demonstrates, the missing persons posters that plastered Manhattan following the collapse of the World Trade Center were images that evoked not the heroic sacrifice that was made but rather the complexity of the lives of the missing themselves and of their relationships to those who love them. Here, the public narrative is challenged by the intensely personal features of lives and deaths that are situated in families and in friendships and in communities-personal features that evoke and convey complexity while simultaneously rendering these almost impossible to express. The descriptions of the missing were both intensely unique and necessarily uniform; indeed, how could you ask after the person you love? How could you express who she or he is on a photocopied flier? These posters and the grief that animated their production created a rupture of the private into the public - a rupture that in some ways thwarts the attempts of the state to make sacrificial sense of the loss.

Exploring other narratives engenders the possibility of painting pictures that disrupt dominant conceptions of who "we" are, and of what that might mean in the politics of the war on terror. Understanding death as sacrifice situates bodies in a grid of social and political intelligibility that often conceals the complexity of the living, dying, and surviving that is at the heart-whatever that might mean-of human being and of human becoming. In many ways, it is the relationship between the living, dying, and surviving, and the ways in which each is in some sense made possible by the other(s), that weave the stories in this volume together. The war on terror is presumed to involve and privilege particular deaths and types of deaths-particular lives and types of lives. One does not include Mexican and other Latino migrants dying of heat and exhaustion in American deserts among the deaths accumulated and articulated within the war on terror. One does not include those who commit suicide in migration detention centers in the United Kingdom or France or Australia. Similarly, one does not include particular lives and kinds of lives in thinking about how the war on terror comes to be produced as such. One does not include the American moviegoer or the SUV (sport utility vehicle) driver or the Internet user in the context of lives that animate the need for the war on terror to be what it is-yet these are the lives whose particular contours and content are made possible by and in this war. And we know that the identification of lives that matter makes our identification of lives that don't possible.

We are mindful of the fact that the ability (which is different from the desire) to ask and answer questions at all rests on the primary assumption that it is the form of the question itself that produces particular economies 
of intelligibility. This enables us to think through the ways in which the questions posed in the context of the war on terror are posed such that only some answers are intelligible and "appropriate." The desire contained in these questions is to make intelligible within a political imaginary whose possibilities are increasingly narrow. One is, in many ways, required to situate oneself legibly in the dominant narratives of the war on terror. But those who become legible (the citizen, the sacrificial hero, the SUV driver) necessarily effect erasure with respect to what is illegible, unintelligible, and to what disrupts (the illegal migrant, the dead soldier, the missing). These erasures are, to be sure, founded in the realm of the conceptual, but they also necessarily have profound material effects on bodies and lives. For example, the conceptual boundary that marks the separation of the United States from Mexico makes possible our identification of some human bodies as "illegal migrants"- bodies that are already breaking down in the heat of the desert. The materiality of these bodies is constituted by the conceptual, but they also constitute and reconstitute the conceptual. As Roxanne Lynn Doty argues in chapter 1, the corpse of Ana Rosa Segura-Marcial, and countless others "whose dreams ended in the blinding glare of [the] sun," literally redraws the border as a space of exclusion and death.

The story of Ana Rosa is not intelligible in the context of the dominant narratives of the war on terror because the war on terror presumes to be only about specific spaces and individuals. In this way, the war on terror actively silences the livings, dyings, and survivings that make its larger claims possible. The war on terror hardens borders-responds to the territorial violation that occurred on September 11-and actively erases many of the lived consequences that follow from the desires of homeland security. Ana Rosa disrupts the dream of security without death.

The identity/security equivalent that the war on terror attempts to define appears to be based on economies of belonging and unbelonging. Yet the identity that the war on terror claims to secure is no security at all. It does not ensure one's life as politically qualified, as worthy of protection, even when one is apparently in possession of that which designates belonging. As David Mutimer argues in chapter 8, Maher Arar's Canadian passport did not afford him the rights and protections to which he was legally entitled. Interrogated and detained at New York's JFK airport as a suspected terrorist, Maher Arar was denied access to Canadian consular officials and was instead deported from the United States to Syria-his birthplace-where he was imprisoned and tortured for over a year. In the imperative to identify himself to the American state at the customs and immigration counter, Maher Arar's answer about who he was became meaningless. The question had already been answered for him by Homeland Security personnel and the Canadian federal police. 
Although the contributors to this volume often work to refuse the questions asked within the context of the war on terror, in the lived realities of everyday existence the capacity to refuse becomes more and more difficult. One finds oneself already inscribed. The requirement to reveal oneself, and the contours of this revealing, are already formed and contained within the logic of the securitizing state. We are in possession of biometric passports; we have our fingerprints scanned at U.S. ports of entry; we produce our documentation on demand; and, when we cannot, we forfeit ourselves as politically intelligible-as eligible-subjects. We enter political space - the customs counter at JFK, for example-and are faced with certain kinds of questions, hoping that our answers will render us sufficiently intelligible that we may pass safely. Sovereign power attempts to capture us, and we are forced to make answer or to have answer made for us in the silence that would be our refusal. The imperative of sovereign power to make known is increasingly overwhelming-increasingly overpowering - but, also, as Anne Orford argues in chapter 10, fundamentally compromised in the awareness that omnipotent sovereign power is already always a failed project.

\section{"Obscene Undersides"}

This volume is also about the possibilities engendered by changing our scholarly imaginaries-by writing differently, by exposing ourselves and the worlds we conjure and encounter to challenge and scrutiny. For many of the contributors, this has resulted in the imperative to find a new voice, one that attempts to rethink and rewrite the subjects of scholarship-one that attempts to rethink the question of what our obligations might be and to whom we might be obligated. As Roxanne Lynn Doty has argued elsewhere:

We may convey to readers illusions of truth with our authorial expertise, but often we are the hideous beings swallowed up by our scholarly clothes, the dancing fools under the fluorescent lights of our paradigms and theories that voraciously consume our thoughts, hammer the soul from our words, and drain our voices of any traces of humanity. ${ }^{1}$

Our invitation to the contributors was partially animated by a sense that International Relations scholarship has often obscured the human lives that are at stake in its conceptualization and its content. Framed through the identification of threat, preemption, security, and war, the dominant narrative of the war on terror as Attack on America produces phantasmic representations. These representations are variously populated by specific 
one-dimensional subjects who are mobilized in support of a political imaginary that makes certain kinds of narratives and responses possible. In this sense, the contributors reveal the violence in the microeconomics of particular human livings, dyings, and survivings, working to explore and expose the relationships between them. Here, we encounter what Slavoj Žižek, reading through Lacan, has called the "obscene underside"2- the recognition that the war on terror operates within the same frame of violence as that which it seeks to oppose. The exposure of the undersides in the context of the "making live" lies in the constitutive need to "let die." The obscene underside of the war on terror is the refugee who sutures his lips and eyelids to mark his abjection, the child in the Woomera detention center whose response to the trauma of her incarceration is to repeat, "Don't touch me I'm dead," the Mexican migrant whose death in the desert constitutes a strategy of "deterrence" that is necessary to prevent others from attempting the crossing, the SUV driver whose realization of "the American dream" is fueled by the persistence of war and its pervasive economy of death.

The contributors to the volume read through these obscene undersides, exposing their animating illogics. Theoretically focused on the relationship between Foucault's governmentality as articulated in Society Must Be Defended and Giorgio Agamben's notion of bare life, the chapters explore and extend the constitution of biopower as a set of regulatory practices that produce spaces of exception in which human beings are stripped of their political subjectivities such that any violence can be committed against them with impunity. This is a project that has to occupy every body-that has to situate all bodies relative to the ability and the imperative to, as Foucault puts it, make live and let die. This is the conceptual move that excises death from the repertoire of sovereign activities-which relegates death to a space of exception. Death is depoliticized. Killing takes place without responsibility, celebration, or remorse. As Foucault argues:

In the right of sovereignty, death was the moment of the most obvious and most spectacular manifestation of the absolute power of the sovereign; death now becomes, in contrast, the moment when the individual escapes all power, falls back on himself and retreats, so to speak, into his own privacy. Power no longer recognizes death. Power literally ignores death. ${ }^{3}$

In the context of sovereign biopolitics, death needs to be made invisible because death, the underside of this politics, also undermines the sovereign claim that its primary activity is to "make live." In other words, death is expunged from the exercise of sovereign power-obscured as a primary 
effect of sovereign power-relegated to these undersides that are subsequently erased. Because sovereign power is understood as "making live," and not killing, it now operates across an apolitical terrain in which its moral credentials are apparently confirmed, thus preempting critique and challenge. Biopolitics hides its death-producing activities under the rhetoric of making live. Exposing death as the obscene underside of sovereign biopower exposes the politics that have been quietly emptied out of the biopolitical. It is death that exposes the biopolitical project of sovereign power. In his exploration of the contours of biopolitical power, Foucault asks:

How can a power such as this kill, if it is true that its basic function is to improve life, to prolong its duration, to improve its chances, to avoid accidents, and to compensate for failings? How, under these conditions, is it possible for a political power to kill, to call for deaths, to demand deaths, to give the order to kill, and to expose not only its enemies but its own citizens to the risk of death? ${ }^{4}$

Part of the answer lies in the identification of a rupture in the field of the "human" that biopower controls: you cannot kill that which is not constituted as "living." It is this process of "desubjectification"-the construction of life as (potentially) bare life-that makes it necessary to read Foucault and Agamben simultaneously. Foucault provides us with a detailed historical account of the transformation of modern sovereign power from the right to "let live and make die" to the right to "make live and let die." Agamben deepens and stretches this transformation, locating the rise of biopower in the Nazi concentration camp and the violent formation of bare life-homo sacer-where the death of some sustains and makes possible the lives of others.

For both Foucault and Agamben, this fragmentation is inherently racialized. We can add that it is also gendered and classed. The fragmentations of race operate concomitantly with the identification of other fragmentationstechnologies of disciplinary power are threaded into the exercise of biopower simultaneously - citizenship is an example, as marked through the technologies of citizenship-the passport is both disciplinary power and biopower-the constant reminder of the boundary, however precarious and chimerical, between belonging and unbelonging.

These narratives take us to the obscene sites of biopower-sites that must be actively de-remembered, depoliticized, and denied. They explore the war on terror not as it is dominantly described by the biopoliticians who underwrite its production, but rather through the sites that are not explored - the sites where human bodies succumb to technologies of death 
and are erased. There are multiple narratives associated with the war on terror that are partially articulated in architectures of sovereign power. These also play out in the spaces that have been politically excised-or rather depoliticized-as sites informed by the dominant conception of what the war on terror signifies. As Mark Lacy argues, this engenders a new imperative for scholarship:

We need to look at how the logic of biopower in the war on terror-the state of emergency that prepares us for new forms of biopolitical control of populations and biocriminals-limits the chances of surviving the precarious life. ${ }^{5}$

\section{Desire/Grief}

The stories in this volume also revolve around the multifaceted experiences of grief and desire. Judith Butler argues that grief and desire are animated and marked by the same "undoing" of the subject. "Something takes hold of you: where does it come from? What sense does it make? What claims us at such moments, such that we are not the masters of ourselves?" ${ }^{\text {The }}$ grief and mourning associated with loss is made possible by the desire that was "always already" present. ${ }^{7}$ For Butler, grief, mourning, and desire contain the possibility of the political—and the possibility of politics:

Many people think that grief is privatizing, that it returns us to a solitary situation and is, in that sense, depoliticizing. But I think it furnishes a sense of political community of a complex order, and it does this first of all by bringing to the fore the relational ties that have implications for theorizing fundamental dependency and ethical responsibility. ${ }^{8}$

Throughout this volume, the contributors mark both grief and desire, which we understand as fundamentally related, both in the experiences that Butler describes and in the mutual constitution of grief and desire in the contexts of the war on terror: the desire to drive the SUV hinges on the grief of the violence and loss for others that makes the fulfillment of that desire possible. The grief of loss and death that emerges in the context of that violence is the condition that animates the desire for a livable life. Similarly, the immobility of the detention camp makes possible the mobility of the citizen; the loss or denial of subjectivity makes possible the politically qualified, eligible member of the contemporary nation-state (precarious as this qualification might be for Maher Arar and others). These are politics animated both by grief and desire. In its turn, grief lays bare all the 
unlivability in the war on terror, exposing the narratives that work to determine who/what counts and who/what does not.

Of course, the war on terror produces grief: lives are lost; people are incarcerated or simply disappear; cities and homes are destroyed. Yet this grief is manifest not only in the obvious spaces, but also in the form of what constitutes-and is felt to constitute-livable and valuable lives; and indeed, the question of grief often foregrounds its own absence in the questions we pose. For example, we operate in a sociopolitical realm that is obsessed with politically qualified "doing" as the only acceptable manifestation of human "being." Doing, claiming, and acting become the sole legitimate forms of qualified human existence. As Engin F. Isin and Kim Rygiel argue in chapter 9, those who are conceptually and physically relegated to spaces where they cannot make claim are reduced to what Agamben calls "bare life"- life that can be killed with impunity. The legitimate and legitimating "doing" is the mandate of the politically qualified subject. And yet, if we recognize grief as a politics, other possibilities for "doing" emerge. Exploring grief might provide opportunities to "do" differently.

It is not always clear within the contours of trauma and mourning exactly where one ought to begin. We recall one painful scene from Sri Lanka in which a man who had discovered that his wife and child had died in the December 26, 2004 Indian Ocean tsunami sat silently on a bridge spanning a swollen river. Bodies and debris floated by in the current. A Canadian Broadcasting Corporation journalist and camera crew approached him and asked him what he was going to do. The man who had lost everything looked up and answered that he did not know what to do. A subsequent interview with a Canadian medical team that had been dispatched to the region involved one of the physicians complaining that no one was doing anything. But what was there to "do" for a man who had lost his whole life- and those whom he loved? The man on the bridge had perceived that there was simply nothing to be done. If he "did" anything at all on that bridge, it was simply to grieve for those he loved. Was his grief not also a "doing"? We believe that it was. Grieving-mourning-is a doing that can disrupt dominant narratives that seek to co-opt and mobilize loss and mourning for violent political projects.

Here, we see a political imperative to cling to grief. In grief, the plans one lays and intentions one forms are destroyed. As Butler argues:

There is losing, as we know, but there is also the transformative effect of loss, and this latter cannot be charted or planned. One can try to choose it, but it may be that this experience of transformation deconstitutes choice at some level. ... I think one is hit by waves, and that one starts out the day with an 
aim, a project, a plan, and finds oneself foiled. One finds oneself fallen. One is exhausted but does not know why. Something is larger than one's own deliberate plan, one's own project, one's own knowing and choosing. ${ }^{9}$

This awareness allows us to recognize that response is not automatic, nor is it animated by a singular possibility. In grief, we are exposed to one another in ways we could not have fully anticipated, and this exposure opens up a range of possibilities for the political.

In the context of a biopolitics that strives to deny the production of death, how might we begin to grieve lost lives? In some ways, this is a question that requires exploration of the interstices between life and deaththe spaces of withdrawal and abandonment that constitute the contemporary states of exception in which more and more human beings find themselves. Livings and dyings are ruptured by survivings that are neither livings nor dyings, but which are otherwise: liminal spaces of abjection that are dangerously difficult to recognize. Where and what is the human body in this politics of exception? We tend to think of grief as tied to particular losses. In the case of death, it is the corpse that occasions the onset of grief and mourning. How do we grieve in a biopolitics whose primary activity is to remove that body from view? How do we grieve those whose bodies are simply devoured by the Sonoran Desert? How do we grieve dead soldiers when they are spirited back from "battlefields" under media whiteouts in body bags that have been rearticulated as "transfer tubes"? How do we grieve those who are neither living nor dead behind the razor wire of Guantánamo Bay, Yarl's Wood, Woomera? As Cristina Masters asks, "how do we grieve for those who have ostensibly been buried alive in prisons such as Guantánamo Bay and Abu Ghraib?" Here, we confront political death that is not properly "death," a state whose horror is as much contained in the unintelligibility of the category as it is in the physical and emotional trauma of abjectivity.

There is a concordant invisibility of these spaces and with those who are desubjected within them, such that they risk further erasure-the risk of complete historical omission. The war on terror has fundamentally relied on cultural technologies of coherent narrative production in spaces whose coherence is not immediately evident. Memory is fundamentally fragmented, both in time and space, and cannot provide a reliable "map." As Kyle Grayson demonstrates, one can even go as far as Leonard Shelby in the film Memento, tattooing images on his body in an effort to "remember" events whose meaning is already immediately lost, fragmented in contextual complexities that cannot be fully recovered in the scripting on/of the body. Cultural productions attempt to solidify a coherent "we" in the face 
of our inherent unruliness, and in the unreliability of our memories, interpretations, and desires. It is the pervasive fear of our unreliability and unruliness that animates national security imperatives, such as the Bush doctrine of preemption, which Cynthia Weber argues articulates an attempt to secure the unconscious mind in the immanence of its potential criminality. In many ways it is this unreliability and unruliness that marks even those within biopower's domain of making live as always already bare life.

\section{A Note on Structure}

The volume unfolds in three related parts: "Bodies, Lives, Deaths," "Cinematics, Culture, Aesthetics," and "Regulation, Securitization, Preemption" constitute a series of different attempts to explore lived lives in the shadow of the war on terror. These sections begin and end in the spaces that the biopolitical fundamentally obscures, and this is the logic through which they both open and close the volume. "Cinematics, Cultures, Aesthetics" (part 2) engages the dominant narratives of the war on terror, exploring the productive spaces through which its logics unfold. The authors in this section illustrate some of the cultural conditions that in turn make possible the content of the opening and closing sections. These are explorations of the sites of the everyday, cultural sites that, although seemingly obscure, are emphatically necessary for the articulation of the war on terror. As such, "Cinematics, Cultures, Aesthetics" interrogates the spaces where the articulation of hegemonic Americanness is both sustained and disrupted.

Cynthia Weber's reading of the film Minority Report identifies the dangers associated with preemption in the drive to securitize the unconscious. Recognizing the subversive content of the film's narrative on security, Cynthia also points to the ways in which the film - and the American political imaginary-makes use of the feminine as supportive and supplementary to the masculinized quest for security and tranquil domesticity. Kyle Grayson, in his analysis of the film Memento, points to what he calls the "delirium" of the American state in the war on terror. Kyle argues that, in its prosecution of the war on terror, the American state is always already unable to perform the "final act"- the failed revenge project insofar as the war on terror can never claim to have "eliminated" the enemy. Following on this point, David Mutimer argues in the closing section of the volume that the war on terror is articulated as an indefinite project in which the certainty of "winning" is permanently deferred.

Through this logic, the war on terror is also working to extend and sustain a particular way of life. For David Campbell, the cultural productions and 
desires connected to the attainment of the American dream implicate particular American (and other western) lived lives in the everyday politics of the war on terror. Indeed, as this section of the book demonstrates, it is not the spectacular violence associated with September 11 that mobilizes Americans as participants in the war on terror but rather the everyday consumptive desires associated with what it is said to mean to be "American." This underwrites the desire for geopolitical control through which a particular version of "Americanness" can be enacted and inscribed. The "national interest," as David demonstrates, is constituted in and by the everyday-in the choices we make about how to live our lives. Mark Lacy points to the textual and cinematic artifacts that work to provide the cultural purchase that emanates from the apparent necessity of the practices and people associated with the war on terror. Mark explores how the American cultural and political imaginary of the Bush administration produces scripts of moral absolution by narrating the administration as comprised of well-meaning, decent men and women caught in dangerous times.

All of the contributions tell us something about the places where the war on terror is playing out. They explore the cultural networks through which the war on terror is circulated and taken up in the experience of the everyday-in our encounters with others via E-mail, in the vehicles in our driveways, in the cinemas of our suburban neighborhoods, and in the articles of our "human interest" columns and magazines. Certain lives are premised and sustained through an entire economy, however fragmented, of literal and metaphorical deaths that in turn produce radically unlivable lives. It is these relationships that this volume seeks to explore.

Finally, while this collection is inescapably academic, it is our hope that the stories contained within it can find resonance both within our professions and across the terrain of the everyday. Though no doubt scholars in earlier and other times have voiced the same, it is our belief that we are currently caught in a particularly dangerous war. It is a war that is elusive and slippery, with concepts and logics that seem seductively simple. As such, it is a war that needs to be exposed and resisted. We hope that this volume will make some small contribution to these and other efforts.

\section{Acknowledgments}

This project originated as a roundtable entitled "Biopolitics: Boundaries, Borders, and the New Terrain of Global Politics," delivered at the 46th Annual Convention of the International Studies Association in March 2005 in Honolulu, Hawai'i. We would like to extend our warm gratitude to both Palgrave and the contributors to this volume for taking the chance on 
us, who proposed this project as graduate students with no established reputations. It is also our custom to thank those who provided us with nonacademic distraction in all the necessary moments. They will know who they are, and we are most grateful.

\section{Notes}

1. Roxanne Lynn Doty, "Maladies of Our Souls: Identity and Voice in the Writing of Academic International Relations," Cambridge Review of International Affairs, 17:2 (July 2004): 377-392, p. 378.

2. Slavoj Žižek, "What's Wrong with Fundamentalism? Part I," http://www.lacan.com/zizunder.htm.

3. Michel Foucault, Society Must Be Defended, trans. David Macey (London: Allen Lane/Penguin, 2003), p. 248.

4. Ibid., p. 254.

5. Mark Lacy, in this volume.

6. Judith Butler, Precarious Life: The Powers of Mourning and Violence (London: Verso, 2004), p. 21.

7. Ibid., p. 23.

8. Ibid., p. 22.

9. Ibid., p. 21. 